\title{
Current Trends in Drug Discovery Research "CTDDR-2010"
}

\author{
A. K. Saxena
}

(C) Springer Science+Business Media, LLC 2010

The 4th International symposium on Current Trends in Drug Discovery Research (CTDDR-2010) is being held during 17-21st February 2010 at Central Drug Research Institute (CDRI), Lucknow. It will be in the spirit of the 1st CTDDR-2001, 2nd CTDDR-2004, and 3rd CTDDR-2007 symposiums organized earlier in this institute and will focus on the innovative drug discovery approaches for infectious and tropical diseases (malaria, filaria, leishmania, HIV, tuberculosis), aging, genetic, metabolic, and endocrine disorders (neurodegenerative, diabetes, obesity, CNS and CVS related disorders, osteoporosis) and cancer. The deliberations shall contain the cocktail of computational endeavors, innovative drug discovery approaches, and in-depth analysis of structure-activity relationships (SAR), new drug targets, and state of art techniques for the syntheses of organic molecules. A preliminary classification of sub-areas for discussions are as Cellular and molecular signaling; Virtual Library Design and Screening; Systems biology; Drugs from nature/ bioprospecting; Molecular Approaches to disease Therapy; Validated therapeutic targets; QSAR, CADD and CAMM; Novel Approaches for generating chemical diversity and for drug discovery; Pharmacokinetics/Pharmaceutical sciences; Translational Research; Preclinical/Clinical trials; Regulatory, ethics and IPR related issues.

The symposium covering the above topics in 19 sessions in 65 lectures, $>275$ posters and is providing a platform to about $>500$ researchers including 45 from other counties including USA, Germany, France, U.K., Switzerland, Brazil, Greece, Hungary, Denmark, Canada, South Africa, Russia, Italy, Netherlands, Egypt, Australia, Singapore, Japan, Jordan, Turkey, South Korea, Bangladesh for lively interactions during the 5 days deliberation.

This special issue covering the abstracts of total presentations gives a fair idea and over all view of the topics to be discussed in this symposium in aforesaid areas

\footnotetext{
A. K. Saxena $(\bowtie)$

Central Drug Research Institute, Lucknow, India

e-mail: anilsak@gmail.com
} 
relevant to drug discovery research in the current scenario. The abstracts are broadly divided into two categories; the first one includes the invited lectures and oral presentations while the later with the poster presentations. On behalf of organizing committee, I like to acknowledge the NovoNordisk, Denmark; CSIR, ICMR, DST, DBT and Ministry of Earth Sciences, New Delhi for funding as well as the members of scientific committee for their cooperation in reviewing the abstracts.

I, as guest editor gratefully acknowledge the support of Prof. Samir Brahmachari, Director General, CSIR (Patron), Dr. T.K. Chakraborty, Director, CDRI (Chairman) for their support and to Prof. Stephen J. Cutler, his team and Birkhauser Boston, USA for providing all out support to successfully bringing out this special issue well in time.

\section{4th International Symposium on "Current Trends in Drug Discovery Research” CTDDR-2010 (Wed. 17th Feb. to Sun. 21st Feb. 2010) Central Drug Research Institute, Lucknow, India}

Local Organizing Committees

$\begin{array}{ll}\text { Dr. Chakraborty T.K. } & \text { Chairman } \\ \text { Dr. Saxena A.K. } & \text { Organizing Secretary } \\ \text { Dr. Dwivedi A.K. } & \text { Treasurer } \\ \text { Dr. Srivastava Ranjana } & \text { Member } \\ \text { Dr. Puri S.K. } & \text { Member } \\ \text { Dr. Raghubir R. } & \text { Member } \\ \text { Dr. Katti S.B. } & \text { Member } \\ \text { Dr. Dikshit D.K. } & \text { Member } \\ \text { Dr. Kundu B. } & \text { Member } \\ \text { Dr. Chattopadhyay N. } & \text { Member } \\ \text { Dr. Bhandari K. } & \text { Member } \\ \text { Dr. Saxena J.K. } & \text { Member } \\ \text { Dr. Tripathi R.P. } & \text { Member } \\ \text { Dr. Sinha Neeraj } & \text { Member } \\ \text { Dr. Kumar Atul } & \text { Member }\end{array}$

Secretarial Assistance

Mr. A.S. Kushwaha

Mr. D.N. Vishwakarma 